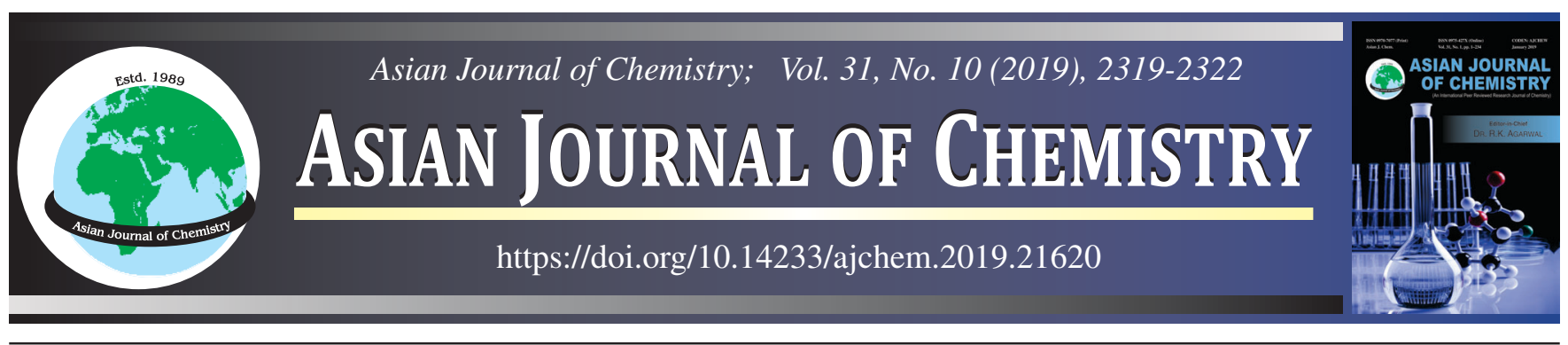

\title{
GC-MS Analysis of Chemical Contents and Physical Properties of Essential Oil of Eucalyptus grandis from PT. Toba Pulp Lestari
}

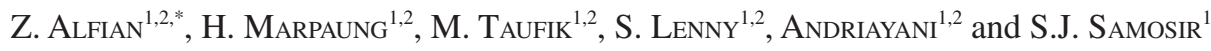

${ }^{1}$ Department of Chemistry, Faculty of Mathematic and Natural Science, Universitas Sumatera Utara, Medan 20155, Sumatera Utara, Indonesia ${ }^{2}$ Pusat Kajian Ipteks Minyak Atsiri Eucalyptus, Universitas Sumatera Utara, Medan 20155, Sumatera Utara, Indonesia

*Corresponding author: E-mail: puieucalyptus@gmail.com

Received: 30 July 2018;

Accepted: 5 June 2019;

Published online: 30 August 2019;

AJC-19543

Essential oils are volatile oils with different compositions according to their source of production and comprise a mixture of substances
having different chemical and physical properties. One of the plants containing essential oil is Eucalyptus grandis grown at PT Toba Pulp
Lestari (Indonesian company). The purpose of this work is to know the chemical contents and physical properties of essential oil from
Eucalyptus grandis as well as to utilize unused leaves at PT. Toba Pulp Lestari to serve as an essential oil. The essential oil of Eucalyptus
grandis leaves was extracted using hydrodistillation method, then essential oil is analyzed by GC-MS. The essential oil of Eucalyptus
grandis leaves was obtained $0.4 \%$. The physical properties test with determination of density and refractive index of essential oil
respectively were obtained at 0.9143 and $1.4653 \mathrm{nD}$ at $29.4^{\circ} \mathrm{C}$. The results of GC-MS analysis of essential oil showed 12 components viz.
$\alpha$-pinene $(45.21 \%)$, camphene $(1.38 \%), \beta$-pinene $(1.11 \%)$, camphogen $(0.74 \%), 1,8$-cineole $(36.55 \%), \alpha$-campholene aldehyde $(0.73$
$\%)$, pinocarvone $(0.83 \%), \alpha$-terpineol $(8.87 \%), \beta$-caryophyllene $(1.72 \%)$, spathulenol $(0.84 \%)$, elemol $(0.85 \%)$ and 1 -nonadecene
$(1.17 \%)$. |

Keywords: Essential oil, Eucalyptus grandis, GC-MS.

ᄂ _ - - - - - - - - - - - - - - - - - - - - - - - - - - - -

\section{INTRODUCTION}

A company of Indonesia, PT Toba Pulp Lestari cultivates eucalyptus tree on the grounds because this plant is the lowest in terms of water consumption (evapotranspiration). This plant is a type of tree that is fast-growing and water-efficient compared to other plants such as acacia and pinus. Eucalyptus consumed only $46 \%$ lower than that of pinus $61.5 \%$ and acacia $68.8 \%$ of water [1]. Several factors make the company keep eucalyptus as the main ingredient of pulp making. Eucalyptus plant cultivation for the needs of the plant is not expected to be a trigger of drought in the area of Toba lake.

At present, the company only produces pulp from the eucalyptus tree and the company's products are marketed world wide. Besides leaves, twigs and bark of this plant can be processed further to become essential oil that has not been done economically [2]. Essential oils can be obtained by distillation from leaves, twigs or tree trunks [3]. Almost all the plants of essential oil sources are already known as long-established crops. Atsiri oil was originally known since 3,000 B.C. by the people of Egypt and used for religious purposes, medication, or as a balm to preserve bodies [4]. Since ancient times, the use of essential oils in Indonesia is still limited and still traditional $[1,5]$. The use of essential oils of plants is traditionally done by soaking aromatic plants with water or in coconut oil $[6,7]$.

Eucalyptus oil is a clear liquid having aroma characteristics of the particular species from which they are obtained. Like other essential oils, they are a mixture of organic compounds (especially terpene) [8]. The composition of oil depends primarily on genetic factors rather than environmental factors [2]. The eucalyptus species from which oil is obtained is the most important factor determining its quality and usage [9]. Several researchers have conducted a study on the essential oil study on Eucalyptus urophylla age 4 years at PT. Toba Pulp Lestari. The results showed that the highest oil content was found in leaves and the quality of oil produced had a cineole content $(45 \%)[10,11]$.

This is an open access journal, and articles are distributed under the terms of the Attribution 4.0 International (CC BY 4.0) License. This license lets others distribute, remix, tweak, and build upon your work, even commercially, as long as they credit the author for the original creation. You must give appropriate credit, provide a link to the license, and indicate if changes were made. 
Based on the above background, the authors are interested in analyzing the chemical content and physical properties to take advantage of leaf waste from Eucalyptus grandis plant in the area of PT. Toba Pulp Lestari to produce essential oils. The volatile oil from the leaf was isolated through the hydrodistillation process and continued by chemical content analysis using GC-MS method then the oil obtained was tested its physical properties $[9,12,13]$. This study aims to determine the physical properties and the chemical composition of Eucalyptus grandis leaves grown in the area of PT. Toba Pulp Lestari by using the GC-MS.

\section{EXPERIMENTAL}

Eucalyptus leaves were collected from the industrial forest of PT. Toba Pulp Lestari in North Sumatera of Indonesia. The plant was identified at the Herbarium Medanense (Meda) Laboratory, Department of Biology, University of North Sumatra, Indonesia.The leaves were then washed by using distilled water, dried, chopped and stored at room temperature.

The specifications instrument GC-MS QP 2010S Shimadzu, using Column Abdel 5MS with the type of ion source Electron Impact, injector temperature: $3000{ }^{\circ} \mathrm{C}$, carrier temperature: $500{ }^{\circ} \mathrm{C}$; carrier: helium; gas flow rate of the carrier: $1.0 \mathrm{~mL} /$ min; temperature oven: $500{ }^{\circ} \mathrm{C}$ for $5 \mathrm{~min}$ then $2400{ }^{\circ} \mathrm{C}$ for 7 min; Ionization electron: $70 \mathrm{ev}$.

Sample preparation: Leaves were selected along with branches $5-15 \mathrm{~cm}$ long from the stem of the plant. The plant collection were conducted in the morning at 7 a.m.

Extraction process: Eucalyptus grandis leaves (150 g) have been cut into small pieces and put into a $1000 \mathrm{~mL}$ base flask and then added sufficient aquadest, connected with a distillation apparatus and heated for $5-6 \mathrm{~h}$ at $100{ }^{\circ} \mathrm{C}$ to produce oil and distillation terminated when the distillate becomes clear yellow. The essential oil obtained is stored in Erlenmeyer flask. The distillate obtained is a mixture of oil and water. Then the oil layer is added $\mathrm{CaCl}_{2}$ anhydrous to bind water that may still be mixed with essential oil, the oily layer is decanted and inserted into the vial bottle, then the essential oil is stored in the refrigerator, sealed and wrapped with aluminum foil so that volatile oil does not evaporate.

GC-MS analysis of eucalyptus oil: A sample of $1 \mu \mathrm{L}$ is injected into GC-MS. Only conditions are adjusted to the condition of each piece of equipment and then observed mass chromatogram generated was interpreted [12].

Preparation of standard sineol standard solutions: The standard series used in this sample is sineol respectively 5,10 , 20, 40 and $60 \mu \mathrm{L}$. That were taken using a micro pipette and then added an internal standard of camphor $600 \mu \mathrm{L}$ to each 10 $\mathrm{mL}$ flask, then diluted with toluene as solvent until the border marker was homogenized. A standard solution of $1 \mu \mathrm{L}$ from each concentration of the standard solution series is injected into the column through the injection site for GC-MS analysis.

GC-MS analysis of sineol levels in eucalyptus oil: The solution of each $1 \mu \mathrm{L}$ standard sineol series was inserted. Only the conditions was adjusted to the conditions of each piece of equipment and then observed mass chromatogram data [14]. The data were used to perform calculations to get the calibration curve.

\section{RESULTS AND DISCUSSION}

The identification results showed that eucalyptus leaf is eucalyptus of Robusta species with plant taxonomy as follows: Kingdom: Plantae, Clade: Angiosperms, Clade: Eudicots, Order: Myrtales, Family: Myrtaceae, Genus Eucalyptus, Species: Eucalyptus grandis W. Hill ex Maiden [5].

Eucalyptus grandis leaf essential oil on distillation was $1.8 \mathrm{~mL}$ with leaves of $450 \mathrm{~g}$ and the percentage is $0.4 \%$. Eucalyptus oil quality requirements according to SNI 06-39542006 are shown in Table-1.

\begin{tabular}{|c|c|}
\hline \multicolumn{2}{|c|}{$\begin{array}{c}\text { TABLE-1 } \\
\text { EUCALYPTUS OIL QUALITY REQUIREMENTS } \\
\text { (ACCORDING TO SNI 06-3954-2006) }\end{array}$} \\
\hline Type of test & Terms \\
\hline Colour & Clear until greenish yellow \\
\hline Odour & Typical eucalyptus \\
\hline Density & $0.900-0.930$ \\
\hline Refractive index & $1.450-1.470$ \\
\hline Solubility in ethanol & $1: 1$ up to $1: 10$ clear \\
\hline Rotary optic & $-4^{\circ}$ up to $0^{\circ}$ \\
\hline Cineole content $(\%)$ & $50-65$ \\
\hline
\end{tabular}

In terms of physical properties, the essential oil leaves Eucalyptus grandis was obtained as clear yellow solution. The odour produced by essential oil was almost the same as the smell of eucalyptus oil which has a spicy, fresh and breathable scent. The weight of essential oil was found be $0.9143 \mathrm{~g}$ and its refractive index was 1.4653. Cineole content of essential oil was $0.08827 \mathrm{~g}$, with a percentage area of $36.55 \%$. Based on SNI No. 06-3954-2006, cineole content is found in the range of 50-65\%. Cineole in volatile oil was one of the main constituent compounds while $\alpha$-pinene as the main compound. In this study, the method used is the distillation of water, which is a simple method but lacks to control the vacuum, so results in the evaporation on essential oils mainly cineole.

The essential oil of Eucalyptus grandis leaf was analyzed by GC-MS in order to determine the chemical contents present therein and the results were adjusted with Library Wiley 229 and NIST Library [12]. Based on the chromatogram of essential oil of Eucalyptus grandis leaves, there are 12 peaks and these are fragmented and interpreted as shown in Table-2. The chemical constitutents of Eucalyptus grandis leaf contained 12 compounds are $\alpha$-pinene $(45.21 \%)$, camphene $(1.38 \%), \beta$-pinene $(1.11 \%)$, camphogen $(0.74 \%), 1,8$-cineole $(36.55 \%), \alpha$-campholene aldehyde $(0.73 \%)$, pinocarvone $(0.83 \%)$, $\alpha$-terpineol $(8.87 \%)$, $\beta$-caryophyllene (1.72 \%), spathulenol (0.84 \%), elemol $(0.85 \%)$ and 1-nonadecene $(1.17 \%)$.

Table-2 shows that the four compounds have the highest percentage of areas, which are $\alpha$-pinene $(45.21 \%), 1.8$-cineole or eucalyptol (36.55\%), $\alpha$-terpineol (8.87\%) and $\beta$-caryophyllene $(1.72 \%)$.

Mass analysis of $\alpha$-pinene: Peak chromatogram with a retention time of $11.621 \mathrm{~min}$ was compound with the formula $\mathrm{C}_{10} \mathrm{H}_{16}$ molecule. The spectrum (Fig. 1) shows the peak of molecular ions at $m / e 136$ followed by fragments on $m / e 136$, $121,105,93,77,67,53,41,27$. By comparing the spectra obtained with the standard spectrum data library, which was 


\begin{tabular}{cccll}
\hline \multicolumn{5}{c}{ THE COMPOUND OF GC-MS ANALYSIS WITH FRAGMENTATION PEAK DATA } \\
\hline $\begin{array}{c}\text { Peak } \\
\text { No. }\end{array}$ & $\begin{array}{c}\text { Retention time } \\
(\mathrm{min})\end{array}$ & $\begin{array}{c}\text { Relative mass } \\
\text { compound }\end{array}$ & \multicolumn{1}{c}{ Compound } & \multicolumn{1}{c}{ Fragment peak } \\
\hline 1 & 11.621 & 136 & $\alpha$-Pinene & $136,121,105,93,77,67,53,41,27$ \\
2 & 12.096 & 136 & Camphene & $136,121,107,93,79,67,53,41,27$ \\
3 & 13.158 & 136 & $\beta$-Pinene & $136,121,107,93,77,69,53,41,27$ \\
4 & 14.954 & 134 & Camphogen & $134,119,103,91,77,65,51,39,27$ \\
5 & 15.266 & 154 & 1,8-Cineole; eucalyptol & $154,139,125,108,84,81,69,43,41,27$ \\
6 & 18.550 & 152 & $\alpha$-Campholene aldehyde & $152,137,119,108,93,81,67,55,39,27$ \\
7 & 19.812 & 150 & Pinocarvone & $150,135,122,108,91,81,69,53,41,27$ \\
8 & 20.795 & 154 & $\alpha$-Terpineol & $136,121,107,93,81,59,43,41,27$ \\
9 & 27.766 & 204 & $\beta$-Caryophyllene & $204,189,175,161,147,133,120,105,93,79,69,55,41,27$ \\
10 & 32.123 & 220 & Spathulenol & $205,187,177,159,147,131,119,105,91,79,69,43,41,27$ \\
11 & 32.507 & 222 & Elemol & $204,189,161,149,135,121,107,93,81,59,43,28,27$ \\
12 & 32.786 & 266 & 1-Nonadecene & $266,154,140,126,112,111,97,83,57,41,27$ \\
\hline
\end{tabular}

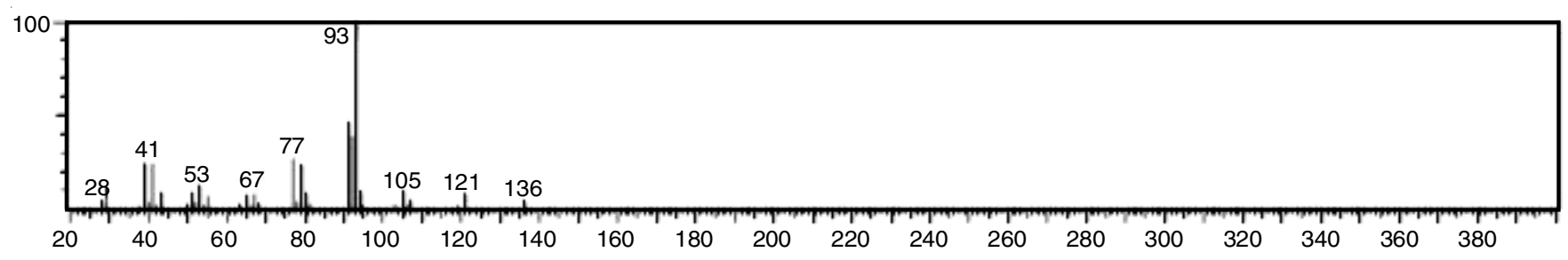

Fig. 1. Mass spectra of $\alpha$-pinene

found closer to the possible compound was $\alpha$-pinene as much as $45.21 \%$.

Mass analysis of 1,8-cineole: Peak chromatogram with a retention time of 15.266 min was a compound with the formula $\mathrm{C}_{10} \mathrm{H}_{18} \mathrm{O}$ molecule. The spectrum (Fig. 2) shows the molecular ion peak at $m / e 154$ followed by the fragments at $m / e$ $154,139,125,108,84,81,69,43,41,27$. By comparing the spectrum obtained with the standard spectrum data library, which allows found 1,8-cineole as much as $36.55 \%$.

Mass analysis of $\boldsymbol{\alpha}$-terpineol: Peak chromatogram with a retention time of 20.795 min was a compound with the formula $\mathrm{C}_{10} \mathrm{H}_{18} \mathrm{O}$ molecule. The mass spectra (Fig. 3) shows the peak of molecular ions at $m / e 136$ followed by fragments at $m / e$ $136,121,107,93,81,59,43,41,27$. By comparing the spectrum obtained with the standard spectrum data library enabling the compound was $\alpha$-terpineol of $8.87 \%$.
Mass analysis of $\boldsymbol{\beta}$-caryophyllene: Peak chromatogram with a retention time of $27.766 \mathrm{~min}$ is a compound having the molecular formula $\mathrm{C}_{15} \mathrm{H}_{24}$. The mass spectra (Fig. 4) shows the peak of molecular ions in $m / e 204$ followed by fragments at $m / e$ 204, 189, 175, 161, 147, 133, 120, 105, 93, 79, 69, 55, 41,27 . By comparing the spectra obtained with the standard spectral data library enabling the compound was found to be $\beta$-caryophyllene as much as $1.72 \%$.

\section{Conclusion}

GC-MS analysis showed that the clear yellow solution of essential oil of Eucalyptus grandis leaves contained 12 compounds, namely: $\alpha$-pinene, camphene, $\beta$-pinene, camphogen, 1,8 -cineole, $\alpha$-campholene aldehyde, pinocarvone, $\alpha$-terpineol, spathulenol, elemol, $\beta$-caryophyllene and 1-nonadecene.

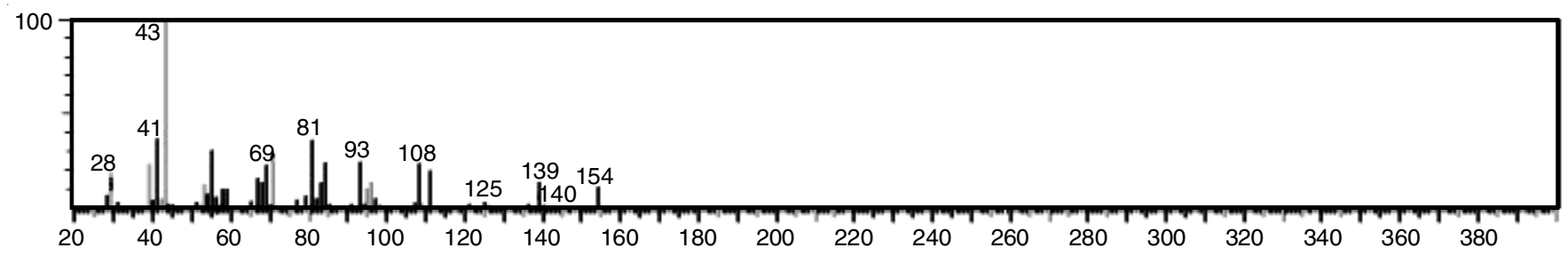

Fig. 2. Mass spectra of 1,8-cineole

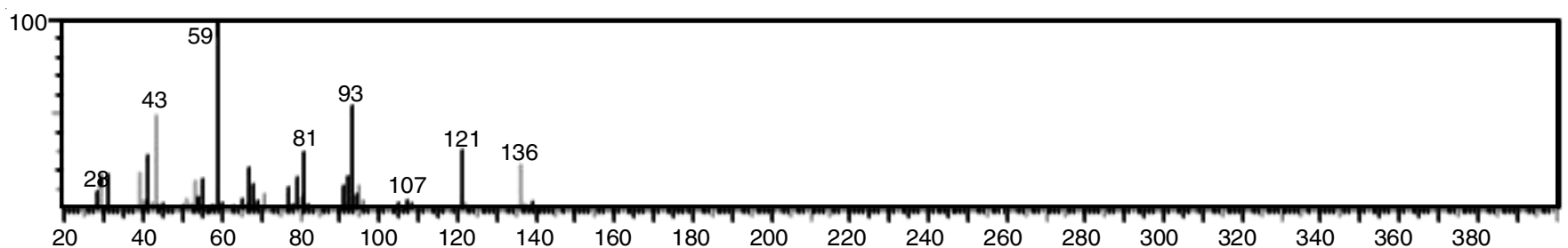

Fig. 3. Mass spectra of $\alpha$-terpineol 


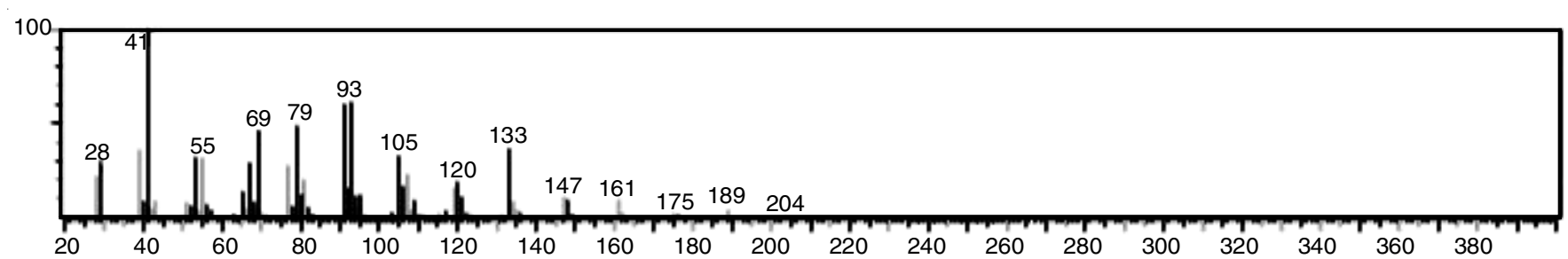

Fig. 4. Mass spectra of $\beta$-caryophyllene

\section{ACKNOWLEDGEMENTS}

This work was supported by Universitas Sumatera Utara (Pusat Kajian Ipteks Minyak Atsiri Eucalyptus) and PT. Toba Pulp Lestari, Tbk, Indonesia.

\section{CONFLICT OF INTEREST}

The authors declare that there is no conflict of interests regarding the publication of this article.

\section{REFERENCES}

1. B.J. Myers, S. Theiveyanathan, N.D. O'Brien and W.J. Bond, Tree Physiol., 16, 211 (1996);

https://doi.org/10.1093/treephys/16.1-2.211.

2. E. Hadji, B. Ndiaye, M.T. Gueye, I. Ndiaye, M. Diop, M.B. Diop and M.-1. Fauconnier, J. Essent. Oils Nat. Prod., 5, 1 (2017).

3. M.N. Boukhatem, M.A. Ferhat, A. Kameli, F. Saidi, K. Walid and S.B. Mohamed, Int. Lett. Chem. Phys. Astron., 36, 303 (2014); https://doi.org/10.18052/www.scipress.com/ILCPA.36.303.

4. K. Mahmoud and S.I. Ali, Int. J. Pharma Bio Sci., 6, 883 (2015).
5. Z. Alfian, M. Taufik, H. Marpaung and I.J. Sibarani, Int. J. Appl. Chem., 14, 255 (2018).

6. M. Hunter, Essential Oils: Art, Agriculture, Science, Industry and Entrepreneurship: A Focus on the Asia-pacific Region, Nova Science Publishers, Inc.: New York (2014).

7. W.N. Setzer, J. Essent. Oils Nat. Prod., 4, 16 (2016).

8. A. Song, Y. Wang and Y. Liu, Asian J. Tradit. Med., 4, 134 (2009).

9. A. Kumar Tyagi, D. Bukvicki, D. Gottardi, G. Tabanelli, C. Montanari, A. Malik and M.E. Guerzoni, BioMed Res. Int., 2014, Article ID 969143 (2014); https://doi.org/10.1155/2014/969143.

10. Y. Wang, X. Li, Q. Jiang, H. Sun, J. Jiang, S. Chen, Z. Guan, W. Fang and F. Chen, Molecules, 23, 166 (2018); https://doi.org/10.3390/molecules23010166.

11. G. Pain, Eucalyptus Oil Applications and Markets, Elder Market Research, Verve Energy (2015).

12. M. Taufik, J. Biomed. Life Sci., 4, 1 (2016); https://doi.org/10.11648/j.ajbls.20160401.11.

13. Z. Alfian, H. Marpaung and M. Taufik, J. STIKNA: J. Sains, Teknol. Farm. Kesehatan, 1, 11 (2017) (in Indonesian).

14. K.M. Taufik, H. Marpaung, J. Gultom and S.L. Raja, Teknol. Farm. Dan Kesehat. STIKNA Medan, 1, 1 (2017) (in Indonesian). 